\title{
БРЕКЗИТ БЕЗ СДЕЛКИ - ВЗГЛЯД ИЗ ЕВРОПЕЙСКИХ СТОЛИЦ
}

Аннотация. Статья посвящена позициям отдельных стран - членов Европейского союза в свете возможного брекзита без сделки. Руководство ЕС полагает, что уступки Лондону создадут опасный прецедент для европейского проекта. Ряд представителей политического истеблишмента ЕС сохраняет собственные озабоченности в отношении неупорядоченного выхода Великобритании из Евросоюза и уже готовит экстренные меры.

Ключевые слова: Соединённое Королевство, брекзит, сделка, Европейский союз, Ирландия, Франџия, Германия, Испания, Польша, Нидерландь, Италия, Швеция.

\section{Отвергнутое соглашение и неопределённость}

Выход Великобритании из Европейского союза стал стресс-тестом для политического истеблишмента Соединённого Королевства и для визави Лондона в рамках европейской интеграции. ЕС отказывается менять соглашение по брекзиту по принципу «торг не уместен», а перспектива брекзита без сделки становится всё более вероятной. По мнению главы Совета ЕС Д. Туска, за безответственную агитацию в пользу выхода из Евросоюза для британских политиков уготовано «отдельное место в аду» ${ }^{1}$

Лондон, в свою очередь, полагает, что переговоры зашли в тупик по вине Евросоюза. Свыше 58\% населения Британии считает, что Брюссель занял слишком жёсткую линию ${ }^{2}$. По словам главы МИД Великобритании Дж. Ханта, ЕС нарушает собственные ценности свободы и демократии и «подобно СССР препятствует выходу из Союза» ${ }^{3}$.

Официальные лица Швеции прямо заявили, что «Великобритания создаёт проблемы не только себе, но и остальным членам евроинтеграции» ${ }^{4}$, имея в виду сложности в ряде межгосударственных сфер, которые сейчас регулируются правилами общего европейского рынка. Первыми под удар «жёсткого» брекзита попадут население и бизнес тех стран, которые имеют сухопутную (Ирландия) или морскую границу с Соединённым Королевством (Швеция, Дания, Германия и Франция).

Руководство по́ртов Роттердама, Антверпена и Гамбурга (транзитные пункты для торговли между Британией и странами - членами ЕC) уже готовят ряд мер на случай «жёсткого» брекзита. Франция объявила, что направит дополнительно 700 сотрудников таможни в Кале,

СГодованюк Кира Анатольевна - кандидат политических наук, старший научный сотрудник Центра британских исследований ИЕ РАН. Адрес: 125009 , Россия, Москва, ул. Моховая, д. 11, стр. 3. $\boldsymbol{E}$ mail: kira.godovanyuk@gmail.com.

DOI: http://dx.doi.org/10.15211/vestnikieran120193035

${ }^{1}$ Donald Tusk's special place in hell looks like where we are right now. URL: https://www.theguardian.com/politics/ 2019/feb/06/donald-tusks-special-place-in-hell-looks-like-where-we-are-right-now (дата обращения 17.02.2019)/

${ }^{2}$ British public thinks the EU has been harsh in negotiations. URL: https://ukandeu.ac.uk/british-public-thinks-the-euhas-been-harsh-in-negotiations/ (дата обращения 17.02.2019).

Brexit: EU figures demand Jeremy Hunt apologise for Soviet comparison. URL: https://www.bbc.co.uk/news/ukpolitics-45712670 (дата обращения 17.02.2019).

${ }^{4}$ Sweden's fury at UK over Brexit: «I cannot forgive them for this!». URL: https://www.express.co.uk/news/ politics/ 1079928/brexit-news-latest-sweden-foreign-minister-margot-wallstrom (дата обращения 17.02.2019). 
Гавр, Дюнкерк ${ }^{1}$. Ирландия предполагает увеличить персонал таможни на 1000 сотрудников².

В ожидании неупорядоченного брекзита в январе 2019 г. парламент Нидерландов (страна поддерживает тесные торговые связи с Британией ${ }^{3}$ ) принял закон, который обязывает кабинет министров в течение десяти недель внести на рассмотрение комплекс мероприятий по снижению негативных последствий для экономики. Правительство выделило 100 млн евро на экстренные меры, включая дополнительный таможенный персонал (900 сотрудников $)^{4}$. Национальное радио запустило информационную кампанию для бизнесменов: «Проследи, чтобы брекзит не встал на твоём пути!».

Дания выразила надежду, что Соединённое Королевство продвинется в сделке с Брюсселем $^{5} 11$ февраля 2019 г. Швейцария ${ }^{6}$ подписала с Великобританией договор с целью защитить торговые связи между странами в случае брекзита без сделки.

\section{Ирландия}

Вступив в европейскую интеграцию одновременно с Соединённым Королевством в 1973 г., Ирландия стремилась построить прочный альянс с Европейским союзом и США. Участие в европейской интеграции помогло Ирландии не только выработать modus vivendi с Лондоном, но и существенно укрепить экономику. После брекзита Ирландия надеется расширить своё влияние внутри ЕС и стать мостом между США и ЕС.

Дублин счёл своей дипломатической победой поддержку Евросоюзом режима открытой границы с Северной Ирландией. Однако брекзит без сделки перечеркнёт эти завоевания и нарушит Белфастские соглашения. Дж. Братон, экс премьер-министр Ирландии, озвучил один из главных «страхов» Соединённого Королевства: «выход из ЕС без соглашения открывает путь к объединению Ирландии» 7 .

Хотя «жёсткий» выход Великобритании из Европейского союза больно ударит по экономике Дублина, он категорически против уступок и дополнительных преференций Лондону. В Плане действий при чрезвычайных обстоятельствах (Contingency Action Plan), опубликованном в декабре 2018 г., правительство предусмотрело ряд экстренных мер на случай брекзита без сделки ${ }^{8}$.

\footnotetext{
${ }^{1}$ France preparing transport and customs measures in case of no-Brexit deal. URL: https://www.reuters.com/article/ukbritain-eu-france-transport/france-preparing-transport-and-customs-measures-in-case-of-no-brexit-deal-idUSKCN1NL0 NR (дата обращения 17.02.2019).

2 1,000 new customs and veterinary inspectors need to be hired in preparation for Brexit - Varadkar. URL: https://www.thejournal.ie/ireland-customs-veterinary-brexit-4135182-Jul2018/ (дата обращения 17.02.2019).

${ }^{3}$ Объёмы торговли Великобритании и Нидерландов не всегда точны из-за «роттердамского эффекта». Под этим термином понимают искусственно завышенную статистику товарооборота между странами, поскольку через порт Роттердама в Соединённое Королевство отправляют товары разного происхождения. Эксперты указывают, что объём товарооборота через данный порт не даёт точной картины торговли ни с Нидерландами, ни с ЕС как крупнейшим торговым партнёром Лондона (44\% общего экспорта и 53\% импорта Британии), поскольку в статистику могут войти товары неевропейского происхождения. Statistics on UK-EU trade. House of Commons Library. Briefing Paper. №7851. 11 January 2019.

${ }^{4}$ EU Brexit panic: Mark Rutte's Dutch Government given emergency powers for no-deal Brexit. URL: https://www. express.co.uk/news/world/1079758/eu-brexit-panic-dutch-mark-rutte-emergency-powers-no-deal-brexit-latest-nether lands?utm_source=traffic.outbrain\&utm_medium =traffic.outbrain\&utm_term=traffic.outbrain\&utm_content=traffic.out brain\&utm_campaign=traffic.outbrain (дата обращения 17.02.2019).

5 Denmark's foreign minister wants close relationship with UK after Brexit. URL:https://www.thelocal.dk/201808 15/denmarks-foreign-minister-wants-closer-relationship-with-uk-before-and-after-brexit (дата обращения 17.02.2019).

${ }_{7}^{6}$ Не входит в ЕС, однако участвует в Шенгенском соглашении и следует ряду европейских директив/

7 Theresa May is leading us towards a highly dangerous no-deal Brexit and a united Ireland. URL: https://www. telegraph.co.uk/politics/2019/02/11/theresa-may-leading-us-towards-highly-dangerous-no-deal-brexit/ (дата обращения 17.02.2019).

${ }^{8}$ Government of Ireland Preparing for the withdrawal of the United Kingdom from the European Union on 29 March 2019 Contingency Action Plan December 2018. URL: https://merrionstreet.ie/MerrionStreet/en/News-Room/Releases/ No_Deal_Brexit_Contingency_Plan.pdf?utm_source=POLITICO.EU\&utm_campaign=febbfc1d09-EMAIL_CAMPAI
} Научно-аналитический вестник ИЕ РАН, 2019, №1 


\section{Франция}

Приоритет Франции в свете брекзита - сохранить единство двадцати семи стран - членов европейской интеграции. Париж рассматривал выход «неудобного» партнёра по ЕС как возможность реформировать и укрепить европейский проект. В Соединённом Королевстве сочли, что Франция стремится «наказать» Великобританию и опасается, что Лондон получит более выгодные условия по сравнению с остальными членами «европейского клуба».

Ещё в 2017 г. президент Франции говорил, что «двери для Британии в ЕС по-прежнему открыты». После того как Палата общин отклонила проект соглашения между Лондоном и Брюсселем, Э. Макрон заявил, что Европейский союз не будет возобновлять переговоры, а британские политики должны сами решать свои проблемы.

Неупорядоченный брекзит, безусловно, создаст ряд проблем из-за правового вакуума в сфере торговли и производственных цепочек. Развернувшаяся «гребешковая война» - один из ярких примеров неурегулированных правовых споров между двумя странами ${ }^{1}$.

С выходом из ЕС Британия выйдет из-под юрисдикции Дублинских соглашений и не сможет возвращать беженцев в другие страны - члены Евросоюза в рамках специальных директив ЕС. В 2018 г. значительно возросло количество незаконных пересечений Ла-Манша просителями убежища (за ноябрь-декабрь 2018 г. более 220 мигрантов на лодках добрались до Британии с берегов Франции $)^{2}$. В свете брекзита контрабандисты активизировали незаконную перевозку людей, опасаясь, что граница между Британией и ЕС будет закрыта.

\section{Германия}

Берлин стремится предотвратить дальнейшую дезинтеграцию Европейского союза, поэтому заинтересован в том, чтобы страны ЕС придерживались единой линии на переговорах с Лондоном. С этой целью Германия взяла на себя негласную роль главного переговорщика по брекзиту. С самого начала Берлин отрицал возможность особого соглашения с Великобританией, способного подорвать единый рынок и стать «опасным» прецедентом.

Британия - пятый по объёмам торговый партнёр Германии после США, Нидерландов, Китая и Франции ${ }^{3}$. Именно поэтому главная обеспокоенность Берлина от неупорядоченного брекзита - правовой и административный хаос, который создаст проблемы бизнесу.

Соединённое Королевство - крупнейший экспортный рынок немецких автомобилей. Ассоциация автопроизводителей Германии предупредила о «фатальных» последствиях брекзита без сделки, который приведёт к повышению цен, высоким таможенным тарифам, усложнит логистику ${ }^{4}$.

Берлин уже начал работу над информационным сайтом для предпринимателей с инст-

GN_2018_12_20_06_34\&utm_medium=email\&utm_term=0_10959edeb5-febbfc1d09-190381597.

${ }^{1}$ В конце августа 2018 г. произошёл инцидент между французскими и британскими рыбаками, которые, по мнению французской стороны, нарушили режим ловли гребешков. В результате британские рыбаки, добывавшие морской деликатес у нормандского побережья, были вынуждены покинуть зону добычи моллюсков. Ловля гребешков происходит в рамках двух юрисдикций. Французский закон разрешает добычу только с октября по май, в то время как британские рыбаки не имеют таких ограничений. В свете брекзита «джентельменское соглашение», позволявшее Британии заниматься добычей гребешков, прекратит действовать. См. подробнее: Scallop war: French and British boats clash in Channel. URL: https://www.bbc.com/news/world-europe-45337091 (дата обращения 17.02.2019).

${ }^{2}$ Channel migrants: Minister defends handling of «crisis». URL: https://www.bbc.com/news/uk-46706381 (дата обращения 15.02.2019).

3 What is Germany planning in case of a no-deal Brexit? URL: https://www.bbc.com/news/world-europe-46798281 (дата обращения 17.02.2019).

4 German carmakers warn hard Brexit would be «fatal». URL: https://www.reuters.com/article/uk-britain-eu-autosgermany/german-carmakers-warn-hard-brexit-would-be-fatal-idUSKCN1PA173 (дата обращения 17.02.2019).

Научно-аналитический вестник ИЕ РАН, 2019, №1 
рукциями как обезопасить свой бизнес от последствий брекзита без сделки. Правительство также намерено нанять дополнительных сотрудников таможенной службы и внести на рассмотрение законопроект, который предусматривает упрощённый порядок пребывания британских граждан на территории Германии (до трёх месяцев без регистрации).

\section{Италия}

Италия изначально поддерживала британское членство в Европейском союзе в расчёте на то, что Лондон сбалансирует франко-германский тандем. Такая цель отвечала стратегическим приоритетам и Соединённого Королевства. Британо-итальянские отношения роднит поддержка НАТО-центристсткой модели европейской безопасности.

Евроскептическое правительство Италии - коалиция «Лиги» и «Движения пяти звезд» рассматривает брекзит как шанс для Рима снизить зависимость от «диктата Брюсселя» (ранее они не исключали вероятность покинуть еврозону). Любые уступки, которые Великобритания получит от ЕС, могут стать «козырем» для будущих переговоров, в том числе по вопросу справедливого распределения миграционного бремени.

Итальянские политики выступили с рядом заявлений в поддержку Лондона. Так, министр внутренних дел М. Сальвини обвинил Брюссель в попытках «мошенничества» на переговорах с Британией и рекомендовал Т. Мэй занять твёрдую позицию1. Министр труда и экономики Л. Ди Майо призвал Европейский союз «не наказывать Лондон»².

В то же время Рим обеспокоен негативными последствиями для итальянской пищевой продукции. Так, национальная конфедерация фермеров уже выразила озабоченность по поводу затруднений экспорта в Британию местных вин в случае брекзита без соглашения ${ }^{3}$. Правительство разрабатывает экстренный план, призванный сохранить торговые связи с Соединённым Королевством, не исключая возможности заключить двустороннее экономическое соглашение с Лондоном ${ }^{4}$.

\section{Испания}

Британия - третий по величине инвестор в испанскую экономику после Нидерландов и Люксембурга 5 . В январе 2019 г. власти Испании приступили к реализации ряда чрезвычайных мер и рекомендаций в тех сферах, которые подвержены негативному воздействию брекзита без сделки: авиасообщение и товарооборот, а также права 150 тыс. испанцев, проживающих в Великобритании.

Между тем, в Испании проживает свыше 300 тыс. британцев (самый большой показатель среди стран ЕС) ${ }^{6}$, поэтому Лондон также заинтересован в зеркальном урегулировании статуса подданных её Величества на территории Королевства Испании.

\footnotetext{
${ }^{1}$ Italy’s hardman Matteo Salvini: EU «swindling» UK over Brexit. URL: https://www.thetimes.co.uk/article/italyshardman-matteo-salvini-eu-swindling-uk-102rb38fb (дата обращения 17.02.2019).

${ }_{2}$ «Stop punishing Britain» Italy Five Star leader demands EU strikes good Brexit deal. URL: https://www.express. co.uk/news/world/913866/brexit-news-european-union-britain-italy-five-star-movement-luigi-di-maio (дата обращения 17.02.2019).

${ }^{3}$ No-deal Brexit WARNING: Italy terrified of Prosecco CRISIS if exports to UK are hit. URL: https://www.express. co.uk/news/politics/1081022/brexit-latest-no-deal-warning-italy-prosecco-uk-supermarkets-brexit-news (дата обращения 17.02.2019).

${ }^{4}$ Italy explores its own bilateral Brexit deal with Britain as its economic crisis nears danger level. URL: https:// www.telegraph.co.uk/business/2019/02/10/italy-explores-bilateral-brexit-deal-britain-economic-crisis/?fbclid=IwAR1 RDrFR5ZfVGOQXUus176PVQd82ijVfqBOW3HX1QAVT64ITG8snoNCEAHs (дата обращения 17.02.2019).

SPAIN: FOREIGN INVESTMENT. URL: https://en.portal.santandertrade.com/establish-overseas/spain/foreigninvestment (дата обращения 17.02.2019).

${ }^{6}$ Brits abroad: how many people from the UK live in other EU countries? URL: https://fullfact.org/europe/how-manyuk-citizens-live-other-eu-countries/ (дата обращения 17.02.2019).
}

Научно-аналитический вестник ИЕ РАН, 2019, №1 
Мадрид намерен разработать специальный веб-сайт для юридических и физических лиц с полезной информацией на случай жёсткого «развода» между Лондоном и Брюсселем.

Позиция Испании вокруг соглашения о выходе Британии из ЕС определена и её претензиями на Гибралтар. Европейский союз признал интересы Испании в отношении спорной территории: вопрос был включён в текст инструкций Совета ЕС по переговорам с Лондоном, а также в проект соглашения ${ }^{1}$. В случае брекзита без сделки Мадрид теряет в лице Брюсселя поддержку и лишается важного козыря на переговорах по статусу Скалы.

\section{Вишеградская группа}

В целом брекзит находится на периферии политического дискурса Польши. Руководство в большей степени занято судебными «баталиями» с европейскими институтами. Однако после выхода Британии из ЕС Польша потеряет ключевого союзника в рамках европейской интеграции. Польша, как и Великобритания, поддерживает линию Брюсселя по сдерживанию России, опасаясь, что Германия и Франция могут отойти от жёсткого курса в отношении Москвы. У стран также совпали взгляды и по вопросу приема беженцев: они противодействовали плану Брюсселя распределить переселенцев по квотам. По словам главы МИД Венгрии, Соединённое Королевство вносит «здравый смысл в дебаты по миграционному вопросу», а с брекзитом страны Вишеградской группы останутся в меньшинстве 2 .

Демонстрируя свою лояльность Лондону, польская сторона потребовала от Брюсселя уступок Т. Мэй ${ }^{3}$.

Главный вопрос для Варшавы - статус 1 млн польских граждан (самая крупная община из мобильных граждан ЕС) ${ }^{4}$ в Великобритании. Премьер-министр Польши М. Моравецкий договорился с Т. Мэй, что права граждан будут гарантированы на взаимной основе даже в случае брекзита без сделки. Чехия и Польша готовятся внести изменение в законодательство, что позволит узаконить пребывание британских подданных на территории этих стран, ожидая взаимные шаги со стороны Лондона 5 .

\section{Выводы}

1. Позиции стран - членов Европейского союза в отношении брекзита зависят от ряда факторов: уровня евроскептических настроений в политическом истеблишменте, степени торгово-экономических связей с Лондоном и количества граждан этих стран, проживающих в Соединённом Королевстве.

2. Благодаря Германии и Франции страны Евросоюза придерживаются единой линии на переговорах с Лондоном, выступая за целостность евроинтеграции как политико-правово́го института.

3. Некоторые евроскептические правительства в Евросоюзе (например, Италия) могут использовать брекзит как рычаг давления на Брюссель.

\footnotetext{
${ }^{1}$ European Council (Art. 50) guidelines for Brexit negotiations.URL: https://www.consilium.europa.eu/en/press/pressreleases/2017/04/29/euco-brexit-guidelines/ (дата обращения 17.02.2019).

2 Hungary complains Brexit will leave it outnumbered in EU. URL: https://www.theguardian.com/politics/2018/ dec/13/hungary-complains-brexit-will-leave-it-outnumbered-in-eu (дата обращения 15.02.2019).

${ }^{3}$ BREXIT BREAKTHROUGH: Poland demands EU give May deal that WILL be supported in Commons. URL: https://www.express.co.uk/news/politics/1080244/brexit-news-poland-theresa-may-deal-latest-eu-juncker-mateuszmorawiecki (дата обращения 15.02.2019).

${ }^{4}$ Brits abroad: how many people from the UK live in other EU countries? URL: https://fullfact.org/europe/how-manyuk-citizens-live-other-eu-countries/ (дата обращения 17.02.2019).

No-deal Brexit: Poland and Czech Republic to allow Britons to stay if UK crashes out. URL: https:// www.theguardian.com/politics/2019/jan/15/poland-and-czech-republic-to-allow-britons-to-stay-if-uk-crashes-out-of-eu (дата обращения 15.02.2019).
}

Научно-аналитический вестник ИЕ РАН, 2019, №1 
4. Вследствие выхода Великобритании из ЕС без сделки останутся неурегулированными правовые основы взаимоотношения Лондона и Брюсселя, торгово-экономические связи и производственные цепочки, но и появятся юридические пробелы на двусторонней основе.

5. Не исключено, что ряд двусторонних соглашений Лондона с отдельными странами европейской интеграции сможет компенсировать отсутствие сделки с Евросоюзом.

\section{References:}

European Council guidelines for Brexit negotiations.URL: https://www. consilium. europa. eu/en/press/press-releases/2017/04/29/euco-brexit-guidelines/

Government of Ireland Preparing for the withdrawal of the United Kingdom from the European Union on 29 March 2019 Contingency Action Plan December 2018. URL: https://merrionstreet. ie/MerrionStreet/en/News-Room/Releases/No_Deal_Brexit_Contingency_Plan.pdf?utm_source= POLITICO.EU\&utm_campaign=febbfc1d09-EMAIL_CAMPAIGN_2018_12_20_06_34\&utm_ medium=email\&utm_term=0_10959edeb5-febbfc1d09-190381597.

Statistics on UK-EU trade. House of Commons Library. Briefing Paper. №7851. 11 January 2019.

Tim Durrant. Alex Stojanovic. Lewis Lloyd. Negotiating Brexit: the views of the EU27. URL: https://www.instituteforgovernment.org.uk/sites/default/files/publications/IfG_views-eu-27v5_WEB.pdf.

\section{No-Deal Brexit - Views from the EU Capitals}

Author. Kira Godovanyuk, Candidate of Sciences (Politics), Senior Research Associate at the UK Studies Center, Institute of Europe Russian,Academy of Sciences. Address: 11-3, Mokhovaya str., Moscow, Russia, 125009. E-mail: kira.godovanyuk@gmail.com.

Abstract. The article considers positions of EU members-states in light of a possible no-deal Brexit. Meanwhile the majority of EU leaders believe that the concessions to the country set to leave the European Union will create a dangerous precedent for the "European project". Some representatives of the European establishment have their own concerns regarding a disorderly no-deal Brexit and considering some measures to counter it.

Key words: UK, Brexit, Brussels, deal, European Union, Ireland, France, Germany, Spain, Poland, Netherlands, Italy, Sweden

DOI: http://dx.doi.org/10.15211/vestnikieran120193035 